Proc. Indian Acad. Sci., Vol. 87 A (E \& P Sciences-4), No. 11, November 1978, pp. 179-191, (C) printed in India

\title{
A numerical technique for simulation of cloud seeding experiments*
}

\author{
A MARY SELVAM, A S RAMACHANDRA MURTY and \\ Bh. V RAMANA MURTY \\ Indian Institute of Tropical Meteorology, Poona 411005
}

MS received 23 May 1978; revised 15 September 1978

\begin{abstract}
Two numerical cloud seeding experiments, using historic rainfall for the Deccan plateau region in Maharashtra state, were performed adopting different simulation techniques. The data used consisted of 1-day total rainfall for the 5-year period 1951-55. A double-area cross-over design with area randomisation was adopted.

The first experiment, EXP-TR, was based on the simulation technique of Twomey and Robertson which involves about $100 \mathrm{hr}$ of Robotron EC-1040 computer time. The second experiment, EXP-MMM was based on a different simulation technique proposed in the present study.

The results of EXP-TR and EXP-MMM have shown close agreement. The numerical simulation technique of EXP-MMM is more promising for the following two reasons: (i) the computational time is reduced by about an order of magnitude without compromising the scientific value of the results, and (ii) a direct estimate of the lower limit of the double ratio value which can be detected at $5 \%$ level of significance is defined.

The results of the two numerical experiments suggested that, for the Deccan plateau region, 15 and $20 \%$ increases in rainfall due to seeding could be detected with $80 \%$ or more probability in 5 years.
\end{abstract}

Keywords. Cloud seeding experiment; numerical simulation; random seeding sequence; double-area cross over design; area randomisations.

\section{Introduction}

The chances of detecting prescribed increases in rainfall due to seeding with a specified degree of confidence can be investigated by numerically simulating the cloud seeding experiments using the historic rainfall data. Such numerical experiments require a great deal of computer time even with the use of high-speed modern computers.

Numerical experiments for selected areas in Australia were reported (Twomey and Robertson 1973; Smith and Shaw 1976). In the numerical simulation technique of Twomey and Robertson an experiment was judged a success if the increase detected was significant at the specified significance level and was between 0.5 and 1.5 times the mean increase for the hypothesised random seeding effect. This arbitrary condition used for detecting the seeding effect is not satisfactory (Das 1976).

A randomised aircraft cloud seeding experiment with a double area cross-over design and area randomisation has been in progress since 1973 in the semi-arid region of the Deccan plateau (Krishna et al 1976). The experiment was conducted during the summer monsoon seasons of 1973, 1974 and 1976 on 39 pairs of days. The rainfall analysis did not indicate statistically significant results.

*An invited state of the art paper 
For evaluating the length of the above cloud seeding experiment for detecting rainfall changes due to seeding with a specific degree of confidence, two numerical experiments were undertaken using the historic rainfall data for the period 195-155. The first numerical experiment, EXP-TR, is based on the numerical technique of Twomey and Robertson (1973). The second experiment, EXP-MMM, is based on a different technique proposed in the present study. EXP-MMM reduces computational time by about an order of magnitude. Also, EXP-MMM defines the lower limit of the double ratio value for the detection of the seeding effect at the $5 \%$ level of significance. The details of the experiment and the results are presented below.

\section{Area and the raingauge network}

The area and the raingauge network are shown in figure 1. Daily total rainfall data obtained from the records of the India Meteorological Department for 32 raingauge stations were used in the study.

The total area is divided into two sectors, Area A and Area B, with 16 raingauges in each sector. The representative area considered for each raingauge is also shown in the figure. The area-weighted rainfall of the two areas (A and B) were computed and used in the study. The area of the numerical experiment includes the area of the aircraft cloud seeding experiment (Krishna et al 1976).

The density of the raingauge network in the area of the numerical experiment is sparse compared to that in the area of the aircraft cloud seeding experiment (Krishna et al 1976). However, this limitation may not affect the results of the present study since the results of a similar numerical experiment in the Western Victoria, Australia, suggested that there will not be much to be gained in increasing the density of rain-

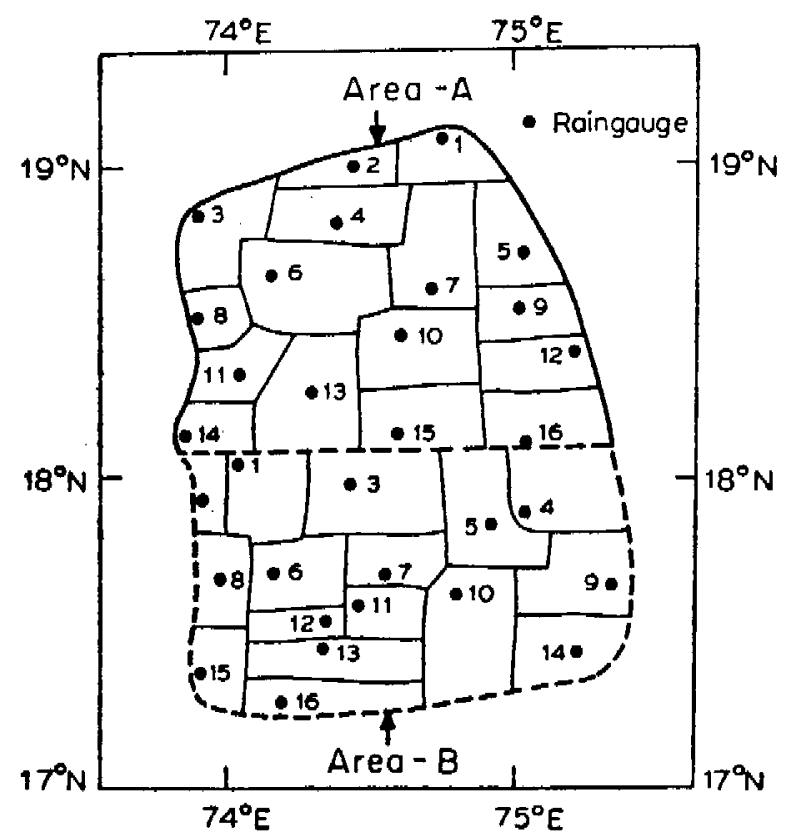

Figure 1. Area of the numerical experiment and the raingauge network 
gauges beyond I gauge per $1000 \mathrm{~km}^{2}$ (Smith and Shaw 1976). The optimum density of raingauges would however be mainly dependent on the spatial variability of rainfall in the region.

Also, a buffer area was considered in the aircraft cloud seeding experiment whereas no buffer area was considered in the present numerical experiment.

\section{Meteorological conditions}

The area of the numerical experiment is located on the leeside of the western ghats with an average elevation of $600 \mathrm{~m}$ above sea level. The characteristics of the summer monsoon circulation and monsoon rainfall have been reviewed (Ananthakrishnan 1977). Some relevant features are mentioned below.

The air flow in the lower troposphere during the summer monsoon (JuneSeptember) is w sterly and large influx of moisture is brought inland from the Arabian sea. S enoptic and mesoscale disturbances leading to low level convergence and vertical moytion of the humid air give rise to continuous to intermittent rain from stratiform clouds. The annual rainfall in the area varies from 30 to $75 \mathrm{~cm}$. About $75 \%$ of the annual rainfall is received during the summer monsoon.

\section{Simulation of the cloud seeding experiments}

Two numerical experiments, EXP-TR and EXP-MMM were simulated for doublearea crossover design with area randomisation. The experiments were performed for 5-year duration using the 1-day total rainfall of the summer monsoon (11 June to 30 September) for the period 1951-55. The period 1951-55 was chosen as the daily rainfall data were readily available for the study. The effect of the possible trends in rainfall records has not been examined in the present study.

The simulated increases in rainfall due to seeding were $5,10,15$ and $20 \%$. The computations were performed using the Robotron EC-1040 computer (equivalent to IBM 360/44) of the India Meteorological Department. The details of the rainfall data used and the relevant statistical parameters of the rainfall for the two areas $A$ and $B$ are given in table 1 .

Correlation coefficients between the rainfall of pairs of raingauge stations were also determined for all possible combinations of 32 raingauge stations in the total area. In $95 \%$ of the total number of pairs of raingauges the rainfall was positively correlated with significance levels of $5 \%$ or lower.

Table 1. Details of rainfall data used in the numerical experiments

\begin{tabular}{lccccc}
\hline $\begin{array}{l}\text { Experiment } \\
\text { duration }\end{array}$ & $\begin{array}{c}\text { Rainfall } \\
\text { period }\end{array}$ & $\begin{array}{c}\text { Total number } \\
\text { of rainfall } \\
\text { periods }\end{array}$ & $\begin{array}{c}\text { Mean rainfall for } \\
\text { each period in mm } \\
\text { Area }\end{array}$ & $\begin{array}{c}\text { Area } \\
\text { B }\end{array}$ & $\begin{array}{c}\text { Correlation } \\
\text { coefficient } \\
\text { rainfall of Area } \\
\text { and area B }\end{array}$ \\
\hline $\begin{array}{l}5 \text { years } \\
(1951-55)\end{array}$ & 1-day & 560 & $\begin{array}{c}3 \cdot 1 \\
(5 \cdot 1)^{*}\end{array}$ & $\begin{array}{c}3 \cdot 3 \\
(4 \cdot 6)^{*}\end{array}$ & $0 \cdot 65$ \\
\hline
\end{tabular}

*Figures in brackets indicate the standard deviations. 


\subsection{Numerical experiment EXP-TR}

This experiment consisted of main experiments and sub-experiments. The significance of the double ratio values of any one main-experiment was determined by performing 100 sub-experiments.

The rainfall for a given area for the prescribed length of time ( 5 years) constituted the original data. The process of 'seeding' an area (A or B) in a particular period (1-day) consisted in generating random numbers representing the percentage increase in rainfall at individual stations within the area, and altering the corresponding rainfall figures accordingly. The methodology is described below.

(i) For each main experiment, a random seeding sequence was generated by taking a random series consisting of zeros and ones and alternating it with a second series by changing zeros to ones and ones to zeros. This procedure was adopted for simulating equal number of seeded and not-seeded periods in the numerical experiments.

(ii) Area A or area B was designated as seeded for the $k$ th period according to whether the $k$ th number in the random seeding sequence generated above was one or zero.

(iii) The hypothesised effect of seeding was simulated by altering the seeded area rainfall by an assigned percentage increase (PERC) according to the random seeding sequence. The increase in rainfall due to seeding was normally distributed among the raingauge stations in the area.

(iv) If the seeded area consisted of $q$ raingauge stations, each station was assigned a random increase in rainfall due to seeding such that the mean increase in the seeded area rainfall was equal to the assigned hypothesised percentage increase with a standard deviation of $1 \%$. The standard deviation of $1 \%$ was chosen assuming that in the real experiment the increase in rainfall would be uniform over a large area. This simple assumption may not hold good in the real experiment.

The change in rainfall due to seeding is estimated by the double ratio $\left(S_{E}\right)$ given below:

$$
S_{E}=\left[\left(\Sigma A_{\mathrm{S}} / \Sigma B_{\mathrm{NS}}\right)\left(\Sigma B_{\mathrm{S}} / \Sigma A_{\mathrm{NS}}\right)\right]^{1 / 2}
$$

where the subscript $S$ refers to the seeded rainfall and NS to the not-seeded rainfall for the two areas $A$ and $B$.

The above procedure was repeated for each main experiment using different random seeding sequences. The number of main experiments conducted was 25 in the present case.

\subsection{Significance of $S_{E}$}

The significance of the double ratio $\left(S_{E}\right)$ value obtained from each main experiment was evaluated by performing 100 further sub-experiments. A re-randomisation scheme was used in the sub-experiments.

\subsection{Sub-experiment}

For each sub-experiment the rainfall data as modified by the assigned seeding effect in the main-experiment described in $\S 4.1$ were used. Thus the data sample used in 
the sub-experiments consisted of the rainfalls in not-seeded periods together with the seeded periods rainfalls as modified by the assigned seeding effects. Using the above rainfall data and a different random seeding sequence for each sub-experiment, the double ratio values ( $S_{\text {PERC }}$ ) were computed. The $S_{\text {PERC values corresponding to }}$ the $5,10,15$ and $20 \%$ assigned increases (PERC) in rainfall due to seeding are designated respectively as $S_{5}, S_{10}, S_{15}$ and $S_{20}$.

\subsection{Criteria for significance of $S_{E}$}

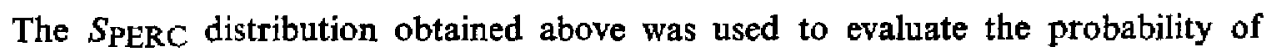
occurrence of $S_{E}$. The significance of $S_{E}$ is given by the probability of occurrence of a $S_{\text {PERC }}$ value equal to $S_{E}$. In the case of an increase in rainfall due to seeding (i.e., for $S_{E}>1$ ) the significance of $S_{E}$ is given by the total number of cases with $S_{\mathrm{PERC}} \geqslant S_{E}$ in the I00 sub-experiments. Similarly for the case of a decrease in rainfall due to seeding (i.e. for $S_{E}<1$ ) the significance of $S_{E}$ is given by the number of cases when $S_{\text {PERC }} \leqslant S_{E}$ in the 100 sub-experiments.

The above method of evaluating the significance of $S_{E}$ does not involve assumptions about the nature of the distribution of $S_{\text {PERC }}$ (Twomey and Robertson 1973) i.e. whether normal or otherwise.

\subsection{Criteria for detection of assigned increase in rainfall due to seeding}

Any increase in rainfall due to seeding in the main-experiment is counted as a detection if the $S_{E}$ value is significant at $5 \%$ level or better. In the present numerical experiment (EXP-TR), 25 values of $S_{E}$ were obtained by performing 25 main experiments. The percentage probability of detection of any assigned increase in rainfall due to seeding was evaluated from the number of detections in the 25 main experiments. Ideally 100 main experiments were required for evaluating the exact percentage probability of detection but the number was restricted to 25 because of the enormous computer time required. 100 main experiments with 100 sub-experiments for each main experiment involve about $100 \mathrm{hr}$ of Robotron EC-1040 (equivalent to IBM $360 / 44$ ) computer time.

\section{Frequency distribution of $S_{\text {PERC }}$}

The cumulative percentage frequency distribution of $S_{\text {PERC }}$ was obtained from the double ratio values of the sub-experiments of EXP-TR ( $(4.1)$. The significance of any $S_{E}$ value can be obtained from the cumulative percentage frequency of $S_{\text {PERC }}$ distribution at $S_{\mathrm{PERC}}=S_{E}$. In the case of an increase in rainfall due to seeding, the cumulative percentage frequency was evaluated starting from the highest value of $S_{\text {PERC. This cumulative percentage frequency distribution is hereafter designated as }}$ $S$ PERC(MAX). Similarly in the case of a decrease in rainfall due to seeding, the cumulative percentage frequency was evaluated starting from the minimum value of $S_{\text {PERC. Th }}$ This cumulative percentage frequency distribution is hereafter designated as $S_{\text {PERC(MIN). }}$

The details of the double ratio values obtained from the sub-experiments of EXPTR are given in table 2. The $S_{\text {PERC distributions were found to be normal }}$ 
Table 2. Statistical parameters of the distributions of the double ratios of the numerical experiments

\begin{tabular}{ccccccc}
\hline Distribution & $\begin{array}{c}\text { Total number } \\
\text { of double } \\
\text { ratio values }\end{array}$ & Mean & $\begin{array}{c}\text { Standard } \\
\text { deviation }\end{array}$ & $\begin{array}{c}\text { Coefficient of } \\
\text { Skewness }\end{array}$ & $\begin{array}{c}\text { Type of } \\
\text { Kurtosis }\end{array}$ & distribution \\
\hline$S_{N}$ & 1000 & 1.0026 & 0.0548 & 0.205 & -0.386 & Normal \\
$S_{8}$ & 1000 & 1.0024 & 0.0549 & 0.199 & -0.367 & Normal \\
$S_{10}$ & 1000 & 1.0025 & 0.0554 & 0.194 & -0.296 & Normal \\
$S_{16}$ & 1000 & 1.0026 & 0.0564 & 0.187 & -0.217 & Normal \\
$S_{20}$ & 1000 & 1.0027 & 0.0572 & 0.164 & -0.119 & Normal \\
\hline
\end{tabular}

1. Standard error for coefficient of skewness $=0.245$

2. Standard error for coefficient of kurtosis $=0.490$

(Chambers 1955). However, the nature of the distribution does not affect the results as mentioned in $\S 4.4$.

\section{Numerical experiment EXP-MMM}

EXP-TR as seen above requires a great deal of computer time. A simple numerical simulation technique which can reduce the computation time by about an order of magnitude, without compromising the scientific value of the results, has been developed and tested with the same input historic rainfall data used in EXP-TR. EXP-MMM enables one to obtain the double ratio values $\left(S_{E}\right)$ of EXP-TR and their significance directly from the historic rainfall data without the need to perform the 100 subexperiments for each of the main experiment. The details of the experiment are described below.

\subsection{Methodology}

For an experiment with a duration of $k$ periods $A_{1}, A_{2}, A_{3} \ldots A_{k}$ and $B_{1}, B_{2}, B_{3} \ldots B_{k}$ represent the period total rainfalls for the areas $A$ and $B$ respectively. For any one particular random seeding sequence of length $k$, the double ratio value of $S_{\mathrm{N}}$ can be obtained from the following relation.

$$
S_{\mathrm{N}}\left[\left(\Sigma A_{\mathrm{S}} / B_{\mathrm{NS}}\right)\left(\Sigma B_{\mathrm{S}} / A_{\mathrm{NS}}\right)\right]^{1 / 2}
$$

The distribution of $S_{\mathrm{N}}$ was obtained starting from the historic rainfall data without any assigned increase in rainfall due to seeding. In the present numerical experiment 1000 values of $S_{\mathrm{N}}$ were obtained using 1000 different random seeding sequences.

From the above distribution of $S_{\mathrm{N}}$ the cumulative frequency distributions of $S_{\mathrm{N}(\mathrm{MAX})}$ and $S_{\mathrm{N}(\mathrm{MIN})}$ were obtained starting respectively from the maximum and minimum values of $S_{\mathrm{N}}$.

As seen from the following, the significance of $S_{\mathrm{E}}$ values of EXP-TR can be directly determined using the $S_{\mathrm{N}}$ distribution of EXP-MMM without petforming the sub-experiments as required in the case of EXP-TR. 
A comparison was made between the cumulative percentage frequency distributions of $S_{\mathrm{N}}$ and $S_{\mathrm{PERC}}$ distributions. For this purpose Chi-square test (Spiegel 1961) was applied to the following distributions:

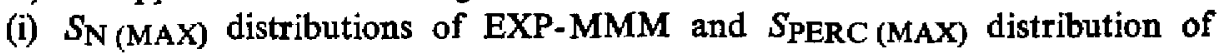
EXP-TR.

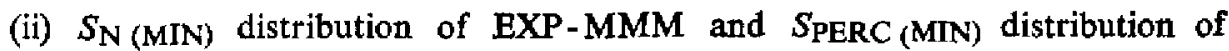
EXP-TR.

The results of the Chi-square test are given in table 3. It is readily seen from the table that the pairs of distributions at (i) and (ii) above are not statistically different. The comparison of the above pairs of distributions was made starting from a value

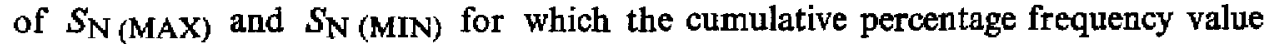
was at least 5 since the Chi-square test cannot be applied for smaller frequencies. This limitation does not alter significantly the percentage probability of detections (table 5).

The percentage significance of $S_{E}$ values as obtained from EXP-TR and as obtained from the $S_{\mathrm{N}}$ distribution of EXP-MMM are shown in figure 2. The values obtained from the two numerical experiments agree closely, particularly for the significance level ranging from $5 \%$ to $0 \%$ which corresponds to the range of significance levels considered for detection of $S_{E}$ values.

From the above statistical analysis it can be readily seen that it is not necessary to perform the 100 subexperiments required for evaluating the significance of any one value of $S_{E}$ of EXP-TR. The significance of $S_{E}$ value can be directly obtained from the $S_{\mathrm{N}}$ (MAX) distribution for values of $S_{E}>1$, and from $S_{\mathrm{N}}$ (MIN) distribution for values of $S_{E}<1$. The number of values of $S_{E}<1$ significant at $5 \%$ level in 100 main experiments gives the percentage probability of detection for the corresponding percentage increase in rainfall due to seeding.

\subsection{Derivation of $S_{E}$ distribution of EXP-TR from the $S_{\mathrm{N}}$ distribution of EXP-MMM}

The percentage probability of detection may also be evaluated by a further shorter method as explained below. In this method the $S_{E}$ values of EXP-TR can be directly obtained from the $S_{\mathrm{N}}$ values of EXP-MMM.

Table 3. Comparison of cumulative pereentage frequency distributions of $S_{\mathrm{N}}$ and SPERC

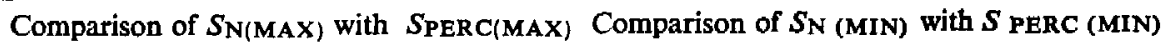

\begin{tabular}{|c|c|c|c|c|c|c|c|c|}
\hline \multirow{2}{*}{$\begin{array}{c}\text { Range of double } \\
\text { ratio }\left(S_{\mathrm{N}}\right)\end{array}$} & & \multicolumn{3}{|c|}{ Chi-square values } & \multicolumn{4}{|c|}{ Chi-square values } \\
\hline & $S_{b}($ MAX) & $\overline{S_{10}(\mathrm{MAX})}$ & $\overline{S_{15} \text { (MAX) }}$ & $S_{90(\text { MAX })}$ & $\overline{S_{5}(\mathrm{MIN})}$ & $S_{1 \alpha(M I N)}$ & $S_{18}(M I N)$ & $\overline{S_{20}(\mathrm{MIN})}$ \\
\hline $\begin{array}{l}0.91 \text { to } 1.00 \\
(10)\end{array}$ & - & - & - & - & $0 \cdot 12$ & 0.38 & 1.02 & $1 \cdot 5$ \\
\hline $\begin{array}{l}1.10 \text { to } 0.85 \\
\text { (26) }\end{array}$ & 0.08 & 0.24 & $0 \cdot 70$ & 1.44 & - & - & - & - \\
\hline $\begin{array}{l}1 \cdot 10 \text { to } 1 \cdot 00 \\
\text { (11) }\end{array}$ & 0.06 & 0.21 & 0.59 & $1 \cdot 27$ & - & - & - & - \\
\hline
\end{tabular}

Figures in brackets indicate the number of pairs for which the comparison was made 


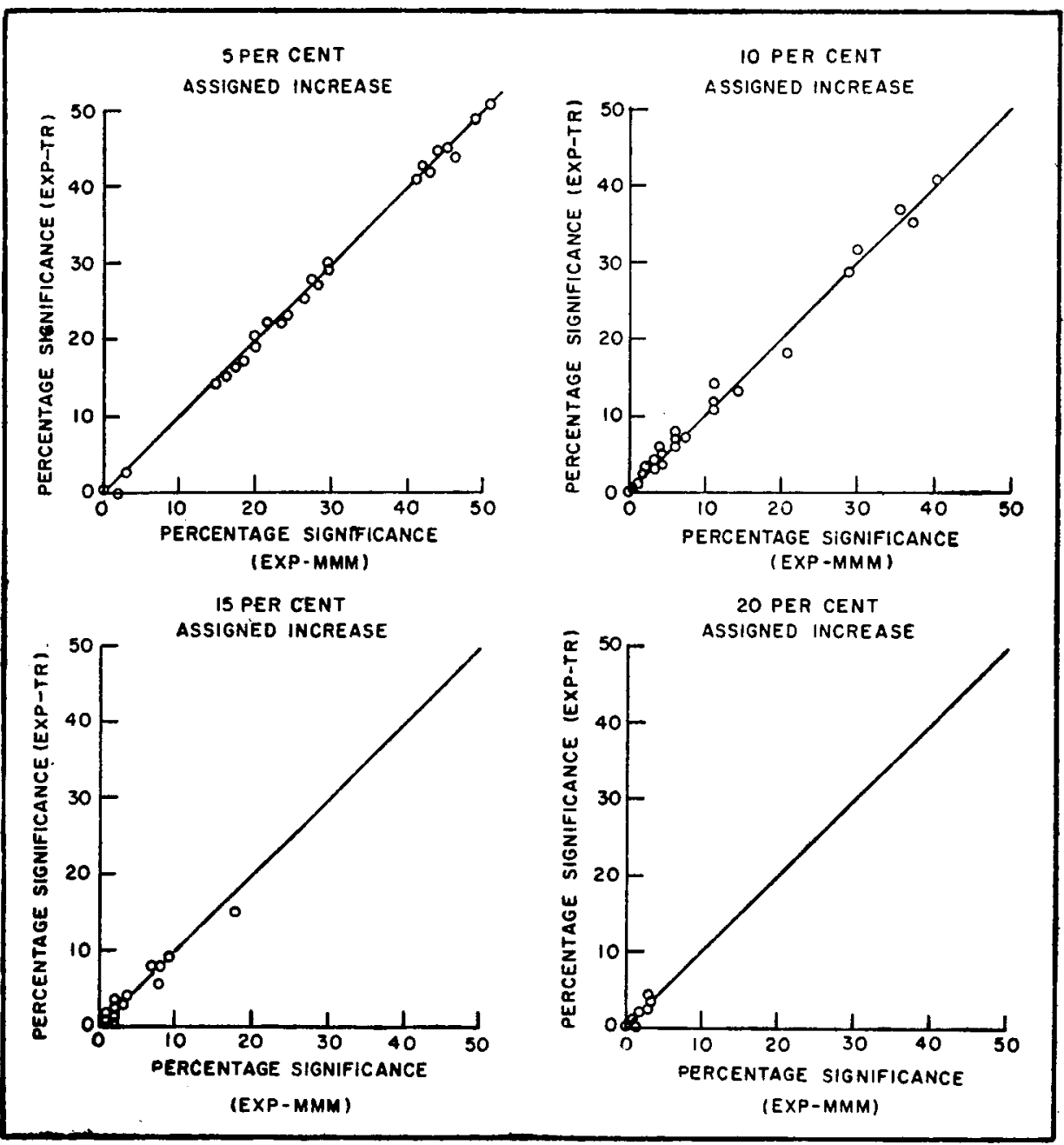

Figure 2. Percentage significance of the double ratio $\left(S_{E}\right)$ values obtained from the numerical experiments EXP-TR and EXP-MMM.

For any one particular random seeding sequence of length $k$, the value of $S_{\mathrm{N}}$ was obtained from equation (2). The experiment was then repeated with the same random seeding sequence as above but with the modified rainfall data due to the assigned increase in rainfall (PERC) due to seeding. The double ratio value was obtained as explained in the following example.

For the case of a $10 \%$ assigned increase in rainfall (PERC) due to seeding the double ratio can be expressed as

$$
S_{E}=\left[\frac{(1 \cdot 1) \Sigma A_{\mathrm{S}}}{\Sigma B_{\mathrm{NS}}} \times \frac{(1 \cdot 1) \Sigma B_{\mathrm{S}}}{\Sigma A_{\mathrm{NS}}}\right]^{1 / 2}
$$

Equation (3) can be expressed as

$$
S_{E}=[1 \cdot 1] \times\left[S_{\mathrm{N}}\right] .
$$


Similarly for any assigned percentage increase in rainfall (PERC) due to seeding (4) can be expressed as follows

$$
S_{E}=\left[1+\frac{\text { PERC }}{100}\right] \times\left[S_{\mathrm{N}}\right]
$$

The $S_{E}$ (MAX) distribution can be derived from the $S_{\mathrm{N}}$ (MAX) distribution using (5).

\subsection{Criteria for detection of the assigned increase in rainfall due to seeding}

For the case of an increase in rain all due to seeding (i.e. for $S_{E}>1$ ) the lowest value of $S_{E}$ which can be detected at the $5 \%$ level of significance is denoted as $S_{D}$. The value of $S_{D}$ can be readily obtained from the $S_{N}$ (MAX) distribution. The value of $S_{\mathrm{N}}$ for which the cumulative percentage frequency is 5 , will give the value of $S_{D}$ (figure 3).

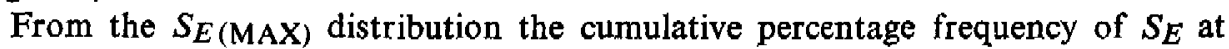
$S_{E}=S_{D}$ will give the percentage probability of detection of the assigned percentage increase (PERC) in rainfall due to seeding.

Thus by adopting the numerical simulation technique of EXP-MMM described above the computation time required in the case of EXP-TR, can be reduced by about an order of magnitude, since in the former methodology there is no necessity of performing $10^{4}$ sub-experiments essential for obtaining the significance of 100 values of $S_{E}$ of the main experiments.

\section{Comparison of results of EXP-TR and EXP-MMM}

The distributions of (i) $S_{E(\mathrm{MAX})}$ obtained from EXP-TR, (ii) $S_{\mathrm{N}(\mathrm{MAX})}, S_{\mathrm{N}(\mathrm{MIN})}$ and $S_{E(\mathrm{MAX})}$ obtained from EXP-MMM are shown in figure 3.

The right half of the peaked graph gives the $S_{\mathrm{N}(\mathrm{MAX})}$ distribution and the left half of the peaked graph gives the $S_{\mathrm{N}(\mathrm{MIN})}$ distribution. The peaked graph is symmetrical on either side of the ordinate at $S_{\mathrm{N}}=1 \cdot 0$. As mentioned in $\S 6 \cdot 1$ the $S_{\mathrm{N}(\mathrm{MAX})}$ and $S_{\mathrm{N}(\mathrm{MIN})}$ obtained from EXP-MMM give the significance levels of values of $S_{E}>1$ and of $S_{E}<1$ respectively. The crosses represent the significance of $S_{E}$ values as obtained from EXP-TR. The $S_{\mathrm{N}(\mathrm{MAX})}$ and $S_{\mathrm{N}(\mathrm{MIN})}$ curves appear to be a good fit for the crosses i.e., the significance levels of $S_{E}$ as obtained from EXP-TR. Since there is a good fit between the results obtained from the two numerical experiments, it can be concluded that the significance of $S_{E}$ values as obtained from EXP-MMM is not very different from those of EXP-TR.

The $S_{E(\text { MAX) }}$ distributions obtained from EXP-TR and EXP-MMM are shown to the right of each peaked graph in figure 3. Chi-square test (Spiegel 1961) was used to compare the distributions. The results are given in table 4. It is readily seen that the distributions obtained from EXP-TR and EXP-MMM are not significantly different.

The comparison of the two distributions was made starting from the value of $S_{E(\text { MAX) }}$ for which the cumulative percentage frequency value was at least 5 since, 


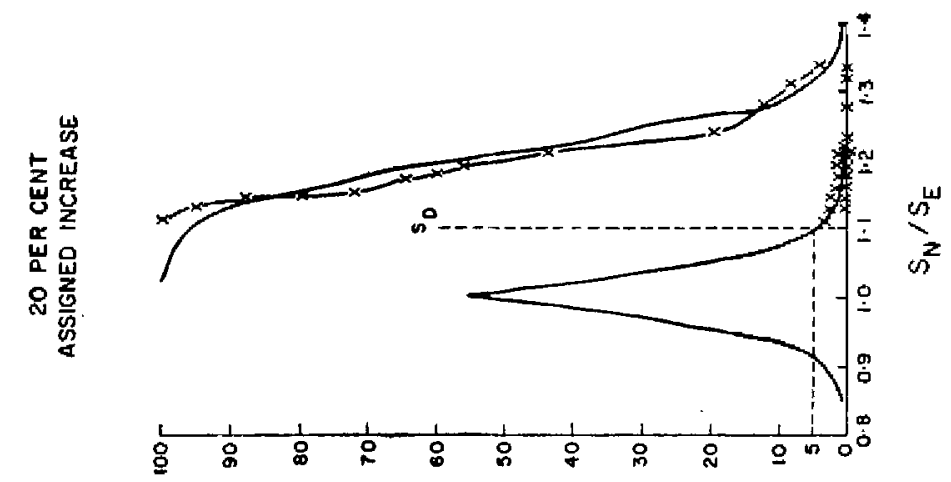

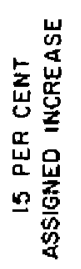
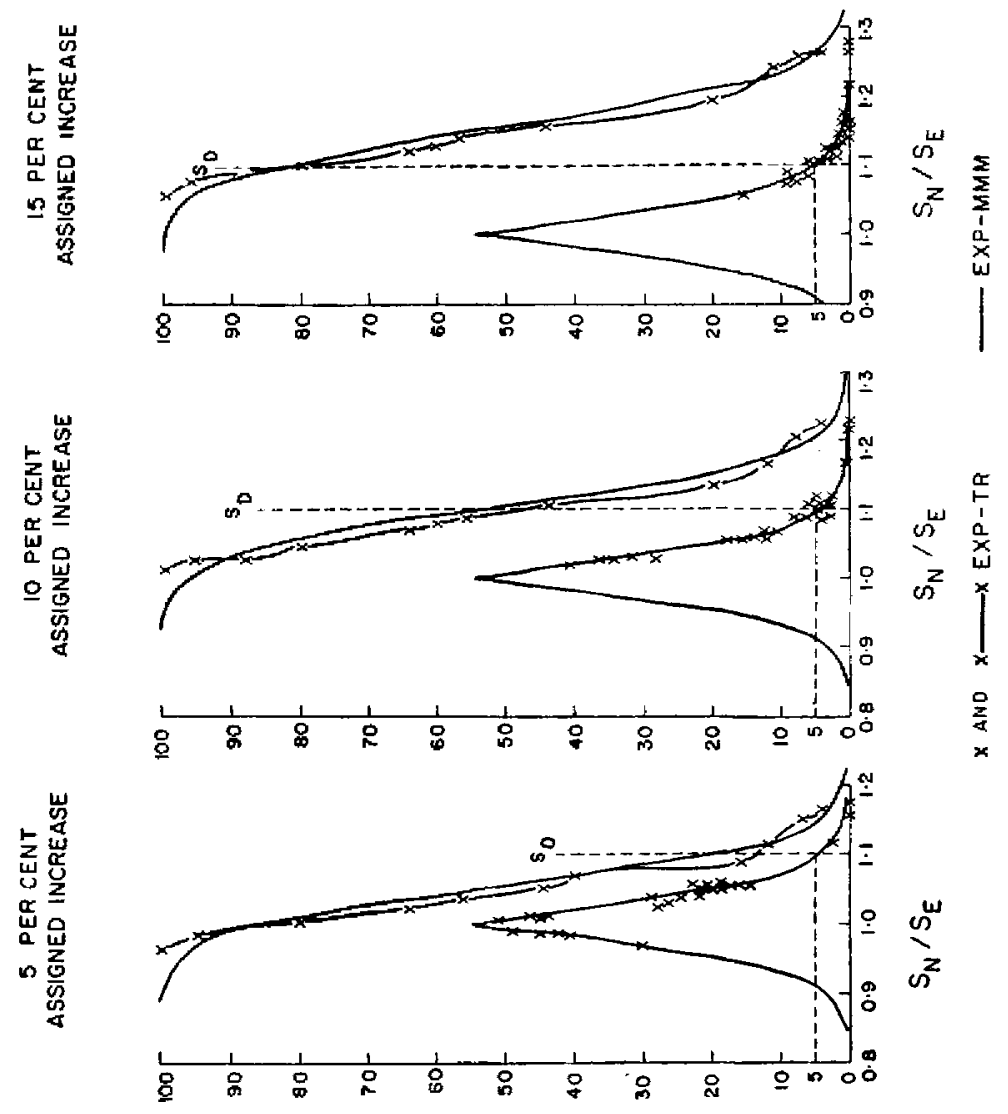

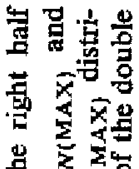

है दे द्वे

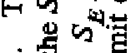

远要

$\sum^{2} \mathrm{~F}$

舟要

总吉

王 0

४ै II

$\bar{x} z \frac{1}{5}$

녕

氙要

田覃

寻安的学

Z马里要

崖宁

5.

㐫要票

它完夏

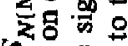

结至

实葛

똡 曾

究总

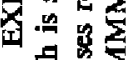

它总

题

在品

结要

0 0 क ते

$\Theta$.

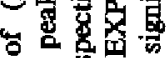

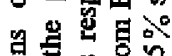

总它点

点的

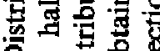

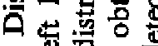

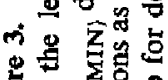

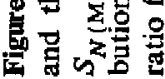


Table 4. Comparison of $S_{\mathrm{E}(\mathrm{MAX})}$ distribution obtained from EXP-TR and EXPMMM using Chi-square test

\begin{tabular}{|c|c|c|}
\hline $\begin{array}{l}\text { Assigned percentage } \\
\text { increase in rainfall } \\
\text { due to seeding }\end{array}$ & $\begin{array}{l}\text { Range of double } \\
\text { ratio }\left(S_{E}\right) \text { values }\end{array}$ & $\begin{array}{l}\text { Chi-square } \\
\text { value }\end{array}$ \\
\hline 5 & $\begin{array}{l}1.15 \text { to } 0.97 \\
\text { (19) }\end{array}$ & $11 \cdot 16$ \\
\hline 10 & $\begin{array}{l}1.19 \text { to } 1.02 \\
\text { (18) }\end{array}$ & 21.02 \\
\hline 15 & $\begin{array}{l}1 \cdot 24 \text { to } 1.06 \\
\text { (19) }\end{array}$ & 20.02 \\
\hline 20 & $\begin{array}{l}1.29 \text { to } 1 \cdot 11 \\
\text { (19) }\end{array}$ & $25 \cdot 90$ \\
\hline
\end{tabular}

Figures in brackets indicate the number of pairs for which the comparison was made.

Table 5. Percentage number of detections obtained from EXP-TR and EXP-MMM

\begin{tabular}{cccc}
\hline $\begin{array}{c}\text { Assigned percentage } \\
\text { increase in rainfall } \\
\text { due to seeding/ } S_{D} \text { value }\end{array}$ & EXP-TR & EXP-MMM & EXP-TR* \\
\hline 5 & 12 & 21 & 22 \\
10 & 44 & 55 & 50 \\
15 & 80 & 80 & 84 \\
20 & 100 & 95 & 100 \\
$S_{D}$ value & - & $1 \cdot 10$ & $1 \cdot 10$ \\
EXP-TR & & & \\
\hline
\end{tabular}

The number of detections in this case has been evaluated using the cumulative percentage frequency distribution of $S_{E}$ of EXP-TR and the $S_{E}$ value obtained from EXP-MMM (see $\S 6.3$ of the text for full explanation). $S_{D}$ is the lowest value of the double ratio $\left(S_{E}\right)$ which can be detected at $5 \%$ level of significance.

the Chi-square test cannot be applied for smaller frequencies. This limitation does not affect the results, for the percentage probability of detection in the present experiment is always above this value and is within the range for which the comparison has been made.

For the case of an increase in rainfall due to seeding (i.e. for $S_{E}>1$ ), the lowest value of $S_{E}$ which can be counted as a detection $\left(S_{D}\right)$ is also shown in figure 3 by a dashed vertical line. The $S_{D}$ value as explained in $\S 6.3$ is obtained from the value of $S_{\text {N(MAX) }}$ for which cumulative percentage frequency is 5 .

The value of $S_{D}$ can be readily obtained from figure 3 , by the ordinate through the point of intersection of the $S_{\mathrm{N}(\mathrm{MAX})}$ curve with the abscissa corresponding to the cumulative percentage frequency value of 5 . The ordinate and the abscissa corresponding to $S_{D}$ are shown by the dashed line in figure 3 .

The results obtained from EXP-TR and EXP-MMM are given in table 5. The percentage probability of detections as obtained from (i) EXP-TR, (ii) EXP-MMM using the $S_{D}$ value and (iii) $S_{E(\text { MAX) }}$ of EXP-TR and the $S_{D}$ value are also given in 
the table. There is a close agreement between the percentage number of detections obtained from EXP-MMM and EXP-TR for the 15 and $20 \%$ assigned increases in rainfall due to seeding. However, for the lower percentage assigned increases $(5$ and $10 \%$ ) the probabilities of detections as obtained from EXP-TR were less compared to those obtained from EXP-MMM. The main reasons for the deviations could be due to the following.

In EXP-TR, the probability of detections in the present numerical experiments were inferred from 25 main experiments instead of from the ideal number of 100 main experiments. With this approximation even the small deviations would be magnified especially when the number of detections were very few as in the case of 5 and $10 \%$ assigned increases in rainfall due to seeding.

\section{Conclasions}

The numerical cloud seeding experiments performed adopting two different simulation techniques and using the historic daily total rainfall data for 5-years (1951-55) for the Deccan plateau region in the Maharashtra State suggested the following.

(i) The numerical simulation technique of EXP-MMM proposed in the present study is promising for investigating numerically the chances of detecting the prescribed increases in rainfall due to seeding.

(ii) The results of the numerical experiment EXP-MMM agreed closely with the results of the numerical experiment EXP-TR, conducted using the simulation technique of Twomey and Robertson (1973).

(iii) The numerical simulation technique of EXP-MMM not only reduces the computation time by an order of magnitude but also provides a direct estimate of the double ratio value which can be detected at $5 \%$ level of significance.

(iv) For the Deccan plateau region, 15 and $20 \%$ increases in rainfall due to seeding could be detected with $80 \%$ and more probability in 5 years duration of the cloud seeding experiment. For smaller percentage increases in rainfall due to seeding, the cloud seeding experiments are required to be continued for more number of years.

(v) The results of the present numerical simulation experiments are to be used with the recognition that the conditions in the real experiment are far from those of the simulated experiment. However, the study would enable to evaluate the possible chances of detecting the prescribed increases in rainfall due to seeding with a specified degree of confidence.

\section{Acknowledgements}

The authors express their indebtedness to Dr R Ananthakrishnan, Ex-Director, Indian Institute of Tropical Meteorology, Poona for the valuable discussions which inspired this research. The help received from $\mathrm{Mr} C \mathrm{~S}$ Bhosale and $\mathrm{Mr} \mathrm{A}$ L Londhe in rainfall data processing is acknowledged. The rainfall data and the Robotron EC-1040 computer time were provided by the India Meteorological Department for which the authors express their gratitude. 


\section{References}

Ananthakrishnan R 1977 Pure Appl. Geophys. 1151209

Chambers E G 1955 Statistical calculations for beginners (Cambridge: University Press) p 24

Das P K 1976 Vayu Mandal 67

Krishna K et al $1976 \mathrm{~J}$. Wea. Modif. 8134

Smith E J and Shaw D E 1976 Papers presented at the Second WMO Scientific Conference on Weather Modification, Boulder, Colorado p. 165

Spiegel M R 1961 Theory and problems of statistics (New York: McGraw Hill) 99

Twomey S and I Robertson $1973 \mathrm{~J}$. Appl. Meteor. 12473 